Department of Public Health and Primary Care, Behaviour and Health Research Unit, University of

Cambridge, UK

2 Department of Social and Policy Sciences, University of Bath, Bath, UK

3 Institute of Health Equity, University College London, UK

Correspondence to: T M Marteau tm388@cam.ac.uk

Cite this as: BMJ 2021;372:n332 http://dx.doi.org/10.1136/bmi.n332 Published: 10 February 2021

\title{
Changing behaviour: an essential component of tackling health inequalities
}

\section{Theresa Marteau and colleagues argue that behavioural and social causes of poor health must be tackled in parallel to reduce inequalities}

\section{Theresa M Marteau, ${ }^{1}$ Harry Rutter, ${ }^{2}$ Michael Marmot $^{3}$}

Life expectancy in England is stalling, while at the same time health inequalities are widening. The 2020 Marmot review of health inequalities in England showed that between 2010 and 2018 the gap in life expectancy at birth between those living in the least and most deprived areas increased. ${ }^{1}$ For men the gap increased from 9.1 to 9.5 years and for women from 6.8 to 7.7 years.

The time people spend in poor health has also increased across England since 2010, from 15.8 to 16.2 years for men, and 18.7 to 19.4 years for women. But these average figures mask an even steeper social gradient than that seen for life expectancy, meaning that those in more deprived areas spend a larger proportion of their already shorter lives in poor health.

The covid-19 pandemic is set to widen these inequalities yet further. ${ }^{2}$ For example, the age standardised mortality rate associated with covid-19 in the most deprived areas in July 2020 was 3.1 deaths/100 ooo population, more than double the rate in the least deprived areas (1.4 deaths/100 ooo population). ${ }^{3}$

Both the 2010 and 2020 Marmot reviews ${ }^{14}$ outline actions in five priority areas for health equity: giving every child the best start in life; good education and lifelong learning to maximise capabilities; fair employment and good working conditions; healthy standard of living for all; and healthy and sustainable places and environments in which to live. However, the 2010 Marmot review included a sixth area-strengthening prevention of ill health-that was omitted from the 2020 review on the basis that it had received more policy focus over the past decade than the other areas. Preventing ill health requires a focus on the behaviours that follow the social gradient and contribute most to chronic disease, including smoking and unhealthy diets. How effective have the policies over the past decade been and how can we do better?

\section{Policies focusing on behavioural causes}

In England, the four leading behavioural causes of years of life lost are tobacco use, unhealthy diet, alcohol consumption, and physical inactivity. ${ }^{5}$ Importantly, all of these behaviours are socioeconomically patterned. Changing them therefore has the potential to increase not only life expectancy but healthy life expectancy, which has a 19 year gap between rich and poor. ${ }^{6}$ Yet despite England announcing some policies on these behaviours in England over the past decade, there has been little effective action.

Most of the relevant policies have centred on childhood obesity. At national level this includes the publication of the childhood obesity plan in 2016 followed by two further chapters in 2018 and 2019. These documents proposed important population level measures, including several that target commercial determinants of health such as advertising and marketing. A soft drinks industry levy was introduced in 2018, and is showing promising effects in both driving reformulation and reducing sales of sugary drinks. ${ }^{7}$ But the other major measures proposed have yet to move beyond the consultation stage. The outgoing chief medical officer for England stated in 2019 that we are "nowhere near achieving" the government ambition to halve childhood obesity by 2030." 8

Policy activity across the three other behavioural causes has been uneven, with some strong action on tobacco control but little on alcohol and physical activity. The 2012 ban on tobacco displays at point of sale was followed by the introduction of standardised packaging in 2016, and the introduction of a minimum excise tax in 2017. The last measure in particular would be predicted to reduce inequalities in smoking, as price based interventions most consistently lead to greater declines in smoking among adults and young people in lower socioeconomic positions than higher. ${ }^{910}$ But although the prevalence of smoking in England has fallen over the past decade, the gap in smoking between those in routine and manual occupations compared with those in other occupations has widened substantially. ${ }^{11}$ Smoking remains the single largest behavioural contributor to the gap in life expectancy between poor and rich people. ${ }^{12}$

English governments have introduced no new policies in the past decade on alcohol control. Minimum unit price, which early findings in Scotland suggest has potential to reduce the social gradient in alcohol harm, ${ }^{13}$ was eschewed in England in 2013. Since then government policies have served to increase rather than decrease the affordability of alcohol, with no notable cuts or freezes in alcohol duty, including in the most recent budget. ${ }^{14}$

The four UK chief medical officers published an update in 2019 of their 2011 guidelines for physical activity, ${ }^{15}$ but no formal policies have been introduced at national level. 


\section{What would effective policy comprise?}

Changing behaviours equitably requires multiple interventions in multiple systems. Policy makers need to work at local, national, and international levels, engaging with the communities they serve. Interventions should include approaches that target high risk individuals as well as those aimed at whole populations. For example, smoking cessation and weight management services can support behaviour change for smokers and people who are overweight, while tobacco taxation and food advertising restrictions influence the behaviours of entire populations.

Two complementary types of interventions can change behaviour: those that target conscious processes and those that target non-conscious processes. Providing personalised risk profiles, for example, requires conscious effort to influence smoking and eating behaviour. ${ }^{16}$ By contrast, changing the context or choice architecture within which a behaviour occurs-for example, by increasing the proportion of healthier foods offered, ${ }^{17}$ requires less conscious effort by an individual to make healthier decisions.

Conscious processes generally make higher demands on people's cognitive, social, and material resources. These resources are not evenly distributed across society, so interventions that rely on them can widen health inequalities. ${ }^{18} 19$ Such effects are known as intervention generated inequalities. Unfortunately, interventions that rely on conscious processes have dominated policy responses to health inequalities in England since the 1970s. ${ }^{20}$

Interventions with most promise for both improving population health and reducing the gap between the poorest and the richest are those aimed at whole populations using interventions that largely target non-conscious processes. They include fiscal and economic interventions, marketing approaches, and interventions altering the availability of products that harm health..$^{21-23}$

\section{Tackling behavioural and social causes in parallel}

The behavioural causes of health inequalities-tobacco use, unhealthy diet, alcohol consumption, and physical inactivity 5-share several drivers with the social causes. These include factors such as unequal distribution of income, goods and services, education, employment, and power, ${ }^{24}$ and, importantly, poverty-with its attentional, emotional, and material consequences.

Intervening on the social determinants can therefore also have a positive effect on the behavioural determinants. For example, increasing household incomes in the poorest households can increase spending on fruit and vegetables ${ }^{25}$ and reduce spending on tobacco and alcohol, ${ }^{25-27}$ perhaps by reducing stress in these households. ${ }^{26} 27$

But such effects, while welcome, are insufficient on their own to change behaviours at the scale needed to reduce the health inequalities. It is also necessary to tackle the drivers of the behavioural causes that are not shared with the social causes.

One set of drivers that shapes much of the routine, habitual, and impulsive behaviour contributing to health inequalities is the stimuli or cues that surround us in physical, economic, digital, social, and commercial environments. Cues that encourage unhealthy behaviours such as the presence of tobacco, alcohol, and fast food outlets are generally much more prevalent in areas of high deprivation. $^{28}$

Higher densities of tobacco retailers are associated with higher levels of smoking, ${ }^{29}$ including smoking in pregnancy, ${ }^{30}{ }^{31}$ and lower quit attempts. ${ }^{30}$ Equivalent patterns are seen for densities of fast food outlets and the prevalence of obesity in both adults and children, ${ }^{3233}$ and for alcohol retailers and alcohol consumption and harm. ${ }^{34}$ Conversely, cues for healthier behaviour such as physical activity include green spaces, which are twice as likely to be found in towns that are least deprived as in those that are most deprived. ${ }^{35}$ Green spaces are associated with higher self-reported health and mental wellbeing, ${ }^{36} 37$ both outcomes that are lower in more deprived groups.

Removing or reducing the environmental drivers of unhealthy behaviours and replacing them with drivers for healthier behaviours would have beneficial effects across populations, with the largest effects in the areas of highest deprivation. For example, reducing volume and speed of traffic and providing segregated infrastructure such as cycle lanes are associated with increased physical activity through cycling. ${ }^{38}$ Reducing the size of wine glasses and wine bottles reduces alcohol consumption. 3940

Other important environmental drivers of behaviour include price and marketing, for which effective interventions include taxes and regulation..$^{21-23}$ The strongest evidence for the largest improvements in population health and reductions in inequalities is for interventions that reduce the affordability of tobacco and alcohol. ${ }^{23}$ Similar effects seem likely for interventions that reduce the affordability of foods high in fat, sugar, or salt. ${ }^{71}$ Price based interventions with the most promise to increase physical activity are those that increase the affordability of walking, cycling, and public transport, and disincentivise driving. ${ }^{42}$

Price based interventions tend to have larger effects on people with low incomes-that is, those most likely to experience the harms that result from unhealthy products and practices. ${ }^{43}$ Effective marketing interventions include bans or restrictions on advertising and marketing designed to persuade people to consume health damaging products. Reducing exposure of children and adults to alcohol and unhealthy food marketing reduces their consumption of these products, 4445 and anti-tobacco campaigns reduce smoking prevalence and increase quitting rates. ${ }^{46}$

Achieving effective policy action requires strong political and public support to overcome powerful lobbying from commercial organisations that profit at the expense of population health. 4748 Tackling behavioural and social causes together is particularly important for price based interventions. Incomes in the poorest families in the UK fell during the financial crisis of 2008-09, leaving them no higher in 2018-19 than in 2001-02. ${ }^{49}$ But introducing price based interventions without steps to alleviate poverty will rightly lack public support. Calls to address the inequalities revealed and worsened by the covid-19 pandemic ${ }^{50-52}$ have the potential to raise support for effective action.

\section{Conclusion}

The large and growing health inequalities in England described in the Marmot 2020 review can be both stalled and reversed. Although greater policy focus has been given to behavioural causes than social causes of inequalities over the past decade, this focus has not been matched by effective action at the scale needed. Given behavioural and social causes share some but not all drivers, effectively tackling health inequalities requires addressing both behavioural and social causes, in parallel and at a scale commensurate with this huge and growing problem. Tackling health inequalities should now form the core of all policies to build resilient societies post covid-19. 


\section{Key messages}

- The 2020 Marmot review showed that health inequalities in England have widened since 2010

- Prevention of ill health was omitted from the 2020 review on the basis that it had received greater policy focus than social causes

- This policy focus was, however, unmatched by effective action

- Behavioural causes of ill health and inequality-tobacco use, unhealthy diet, alcohol consumption, and physical inactivity-share only some drivers with the social causes

- Effectively tackling health inequalities requires addressing both behavioural and social causes in parallel

Contributors and sources: TMM conceived the idea for this paper following discussions with HR and MM. TMM and HR prepared the first draft of the paper to which MM added conceptual ideas and salient evidence. All authors edited the manuscript before approving the final version. TMM is guarantor of the article.

Competing interests: We have read and understood BMJ policy on declaration of interests and have no relevant interests to declare.

Provenance and peer review: Not commissioned; externally peer reviewed.

1 Marmot M, Allen J, Boyce T, Goldblatt P, Morrison J. Health equity in England: the Marmotreview 10 years on. Institute of Health Equity,

2020.https://cam.ldls.org.uk/vdc_100098983000.0x000001

2 Bambra C, Riordan R, Ford J, Matthews F. The COVID-19 pandemic and health inequalities. J Epidemiol Community Health 2020;74:964-8.pmid: 32535550

3 Office for National Statistics. Deaths involving COVID-19 by local area and socioeconomic deprivation: deaths occurring between 1 March and 31 July 2020. 2020.

https://www.ons.gov.uk/peoplepopulationandcommunity/birthsdeathsandmarriages/deaths/bulletins/deathsinvolvingcovid19bylocalareasanddeprivation/deathsoccurringbetween1marchand31july2020

4 Marmot M, Allen J, Goldblatt P, etal. Fair society, healthy lives: the Marmot review. Institute of Health Equity, 2010

5 Steel N, Ford JA, Newton JN, etal. Changes in health in the countries of the UK and 150 English local authority areas 1990-2016: a systematic analysis for the Global Burden of Disease Study 2016. Lancet 2018;392:1647-61. doi: 10.1016/S0140-6736(18)32207-4 pmid: 30497795

6 Office for National Statistics. Health state life expectancies by national deprivation deciles, England and Wales: 2015-2017. 2017. https://cam.ldls.org.uk/vdc_100063278677.0x000001

7 Scarborough P, Adhikari V, Harrington RA, etal. Impact of the announcement and implementation of the UK soft drinks industry levy on sugar content, price, product size and number of available soft drinks in the UK, 2015-19: a controlled interrupted time series analysis. PLoS Med 2020;17:e1003025. doi: 10.1371/journal.pmed.1003025 pmid: 32045418

8 Davies S. Time to solve childhood obesity: an independent report by the chief medical officer. 2019. https://www.webarchive.org.uk/access/resolve/20191014215140/https://assets.publishing.service.gov.uk/government/uploads/system/uploads/attachment_data/file/837907/cmospecial-report-childhood-obesity-october-2019.pdf

9 Smith CE, Hill SE, Amos A. Impact of population tobacco control interventions on socioeconomic inequalities in smoking: a systematic review and appraisal of future research directions. Tob Control 2020;tobaccocontrol-2020-055874; [Epub ahead of print.] doi: 10.1136/tobaccocontrol-2020-055874 pmid: 32994297

10 Brown T, Platt S, Amos A. Equity impact of interventions and policies to reduce smoking in youth: systematic review. Tob Control 2014;23(e2):e98-105 doi: 10.1136/tobaccocontrol-2013-051451 pmid: 24842855

11 Office for National Statistics. Adult smoking habits in the UK: 2019. 2020. https://www.ons.gov.uk/peoplepopulationandcommunity/healthandsocialcare/healthandlifeexpectancies/bulletins/adultsmokinghabitsingreatbritain/2019

12 Jha P, Peto R. Global effects of smoking, of quitting, and of taxing tobacco. N Engl / Med 2014;370:60-8. doi: 10.1056/NEJMra1308383 pmid: 24382066

13 O'Donnell A, Anderson P, Jané-Llopis E, Manthey J, Kaner E, Rehm J. Immediate impact of minimum unit pricing on alcohol purchases in Scotland: controlled interrupted time series analysis for 2015-18. BMJ 2019;366:15274. doi: 10.1136/bmj.l5274 pmid: 31554617

14 Alcohol Health Alliance. AHA responds to budget 2020. Press release, 11 Mar 2020. https://ahauk.org/aha-responds-to-budget-2020/

15 Department of Health \& Social Care, UK chief medical officers' physical activity guidelines. 2019. https://www.webarchive.org.uk/access/resolve/20190923233125/https://assets.publishing.service.gov.uk/government/uploads/system/uploads/attachment_data/file/832868/uk-chief-medicalofficers-physical-activity-guidelines.pdf

16 Hollands GJ, French DP, Griffin SJ, etal. The impact of communicating genetic risks of disease on risk-reducing health behaviour: systematic review with meta-analysis. BMJ 2016;352:11102. https://www.bmj.com/content/352/bmj.i1102. doi: 10.1136/bmj.i1102 pmid: 26979548
17 Pechey R, Cartwright E, Pilling $M$, etal. Impact of increasing the proportion of healthier foods available on energy purchased in worksite cafeterias: a stepped wedge randomized controlled pilot trial. Appetite 2019;133:286-96. doi: 10.1016/j.appet.2018.11.013 pmid: 30468803

18 McGill R, Anwar E, Orton L, etal. Are interventions to promote healthy eating equally effective for all? Systematic review of socioeconomic inequalities in impact. BMC Public Health 2015;15:457. doi: 10.1186/s12889-015-1781-7 pmid: 25934496

19 Veinot TC, Mitchell H, Ancker JS. Good intentions are not enough: how informatics interventions can worsen inequality. J Am Med Inform Assoc 2018;25:1080-8. doi: 10.1093/jamia/ocy052 pmid: 29788380

20 Kriznik NM, Kinmonth AL, Ling T, Kelly MP. Moving beyond individual choice in policies to reduce health inequalities: the integration of dynamic with individual explanations. J Public Health (Oxf) 2018;40:764-75. doi: 10.1093/pubmed/fdy045 pmid: 29546404

21 Marteau TM, White M, Rutter $\mathrm{H}$, etal. Increasing healthy life expectancy equitably in England by 5 years by 2035: could it be achieved? Lancet 2019;393:2571-3. doi: 10.1016/S0140-6736(19)31510-7 pmid: 31258113

22 World Health Organization. "Best buys" and other recommended interventions for the prevention and control of noncommunicable diseases. WHO, 2017.

23 Bloomberg MR, Summers LH, Ahmed M, etal. Health taxes to save lives: Employing Effective Excise Taxes on Tobacco, Alcohol, and Sugary Beverages. Bloomberg Philanthropies, 2019.

24 Marmot M, Friel S, Bell R, Houweling TA, Taylor SCommission on Social Determinants of Health Closing the gap in a generation: health equity through action on the social determinants of health Lancet 2008;372:1661-9. doi: 10.1016/S0140-6736(08)61690-6 pmid: 18994664

25 Gregg P, Waldfogel J, Washbrook E. Family expenditures post-welfare reform in the UK: are low-income families starting to catch up? Labour Econ 2006;13:721-46doi: 10.1016/j.labeco.2005.10.002

26 Strully KW, Rehkopf DH, Xuan Z. Effects of prenatal poverty on infant health: state earned income tax credits and birth weight. Am Sociol Rev 2010;75:534-62. doi: 10.1177/0003122410374086 pmid: 21643514

27 Jones L, Milligan K, Stabile M. Child cash benefits and family expenditures: evidence from the national child benefit. Can J Econ 2019;52:1433-63. doi: 10.1111/caje.12409

28 Macdonald L, Olsen JR, Shortt NK, Ellaway A. Do 'environmental bads' such as alcohol, fast food, tobacco, and gambling outlets cluster and co-locate in more deprived areas in Glasgow City, Scotland? Health Place 2018;51:224-31. doi: 10.1016/j.healthplace.2018.04.008 pmid: 29747132

29 Pearce J, Barnett R, Moon G. Sociospatial inequalities in health-related behaviours: pathways linking place and smoking. Prog Hum Geogr 2012;36:3-24doi: 10.1177/0309132511402710

30 Chaiton MO, Mecredy G, Cohen J. Tobacco retail availability and risk of relapse among smokers who make a quit attempt: a population-based cohort study. Tob Control 2018;27:163-9. doi: 10.1136/tobaccocontrol-2016-053490 pmid: 28432213

31 Clemens T, Dibben C, Pearce J, Shortt NK. Neighbourhood tobacco supply and individual maternal smoking during pregnancy: a fixed-effects longitudinal analysis using routine data. Tob Control 2018;29:7-14. doi: 10.1136/tobaccocontrol-2018-054422 pmid: 30389809

32 Public Health England. Patterns and trends in child obesity: national and regional data. https://www.gov.uk/government/publications/child-obesity-patterns-and-trends/patterns-andtrends-in-child-obesity-national-and-regional-data

33 Burgoine T, Forouhi NG, Griffin SJ, Wareham NJ, Monsivais P. Associations between exposure to takeaway food outlets, takeaway food consumption, and body weight in Cambridgeshire, UK: population based, cross sectional study. BMJ 2014;348:81464 doi: 10.1136/bmj.g1464 pmid: 24625460

34 Shortt NK, Rind E, Pearce J, Mitchell R, Curtis S. Alcohol risk environments, vulnerability and social inequalities in alcohol consumption. Ann Am Assoc Geogr 2018;108:1210-27. doi: 10.1080/24694452.2018.1431105 pmid: 32154488

35 Goodair B, Kenny M, Marteau TM. Townscapes: England's health inequalities. Bennett Institute for Public Policy, 2020. https://www.bennettinstitute.cam.ac.uk/publications/townscapes-englandshealth-inequalities/

36 Twohig-Bennett C, Jones A. The health benefits of the great outdoors: a systematic review and meta-analysis of greenspace exposure and health outcomes. Environ Res 2018;166:628-37. doi: 10.1016/j.envres.2018.06.030 pmid: 29982151

37 Alcock I, White MP, Wheeler BW, Fleming LE, Depledge MH. Longitudinal effects on mental health of moving to greener and less green urban areas. Environ Sci Technol 2014;48:1247-55. doi: 10.1021/es403688w pmid: 24320055

38 Pucher J, Dill J, Handy S. Infrastructure, programs, and policies to increase bicycling: an international review. Prev Med2010;50(Suppl 1):S106-25. doi: 10.1016/j.ypmed.2009.07.028 pmid: 19765610

39 Pilling M, Clarke N, Pechey R, Hollands GJ, Marteau TM. The effect of wine glass size on volume of wine sold: a mega-analysis of studies in bars and restaurants. Addiction 2020;115:1660-7. doi: 10.1111/add.14998 pmid: 32003493

40 Codling S, Mantzari E, Sexton O, etal. Impact of bottle size on in-home consumption of wine: a randomized controlled cross-over trial. Addiction 2020;115:2280-92. doi: 10.1111/add.15042 pmid: 32270544

41 Scheelbeek PFD, Cornelsen L, Marteau TM, Jebb SA, Smith RD. Potential impact on prevalence of obesity in the UK of a $20 \%$ price increase in high sugar snacks: modelling study. BMJ 2019;366:14786. doi: 10.1136/bmj.14786 pmid: 31484641

42 Martin A, Suhrcke M, Ogilvie D. Financial incentives to promote active travel: an evidence review and economic framework. Am J Prev Med 2012;43:e45-57. doi: 10.1016/j.amepre.2012.09.001 pmid: 23159264 
43 Nghiem N, Wilson N, Genç M, Blakely T. Understanding price elasticities to inform public health research and intervention studies: key issues. Am J Public Health 2013;103:1954-61. doi: 10.2105/AJPH.2013.301337 pmid: 24028228

44 Burton R, Henn C, Lavoie D, etal. A rapid evidence review of the effectiveness and cost-effectiveness of alcohol control policies: an English perspective. Lancet2017;389:1558-80. doi: 10.1016/S0140-6736(16)32420-5 pmid: 27919442

45 Smith R, Kelly B, Yeatman H, Boyland E. Food marketing influences children's attitudes, preferences and consumption: a systematic critical review. Nutrients 2019;11:E875. doi: 10.3390/nu11040875 pmid: 31003489

46 Kuipers MAG, Beard E, West R, Brown J. Associations between tobacco control mass media campaign expenditure and smoking prevalence and quitting in England: a time series analysis. Tob Control 2018;27:455-62. doi: 10.1136/tobaccocontrol-2017-053662 pmid: 28667091

47 Kickbusch I, Allen L, Franz C. The commercial determinants of health. Lancet Glob Health 2016;4:e895-6. doi: 10.1016/S2214-109X(16)30217-0 pmid: 27855860

48 Reynolds JP, Stautz K, Pilling M, van der Linden S, Marteau TM. Communicating the effectiveness and ineffectiveness of government policies and their impact on public support: a systematic review with meta-analysis. R Soc Open Sci2020;7:190522. doi: 10.1098/rsos.190522 pmid: 32218927

49 Tomlinson D, Corlett A, Handscomb K, McCurdy C, Brewer M. The living standards audit 2020. Resolution Foundation, 2020. https://www.resolutionfoundation.org/publications/the-livingstandards-audit-2020/

50 Raleigh V. Covid-19 has exposed 'deep inequalities and stark differences in life expectancy.' King's Fund press release, 12 Jun 2020. https://www.kingsfund.org.uk/press/press-releases/covid19-stark-differences-life-expectancy

51 OECD. Building back better: a sustainable, resilient recovery after covid-19. 2020. http://www.oecd.org/coronavirus/policy-responses/building-back-better-a-sustainable-resilientrecovery-after-covid-19-52b869f5/

52 Marmot M, Allen J, Goldblatt P, Herd E, Morrison J. Build back fairer: the covid-19 Marmot review. The pandemic, socioeconomic and health inequalities in England. Institute of Health Equity, 2020.http://www.instituteofhealthequity.org/resources-reports/build-back-fairer-the-covid-19marmot-review

This is an Open Access article distributed in accordance with the Creative Commons Attribution Non Commercial (CC BY-NC 4.0) license, which permits others to distribute, remix, adapt, build upon this work non-commercially, and license their derivative works on different terms, provided the original work is properly cited and the use is non-commercial. See: http://creativecommons.org/licenses/bync/4.0/. 